\title{
Correlation of androgen receptor and SRD5A2 gene mutations with pediatric hypospadias in 46, XY DSD children
}

\author{
X.H. Fu, W.Q. Zhang and X.S. Qu \\ Pediatric Surgery Department, People's Hospital of Binzhou, Binzhou, \\ Shandong Province, China \\ Corresponding author: X.S. Qu \\ E-mail: qxs0608@163.com \\ Genet. Mol. Res. 15 (1): gmr.15018232 \\ Received December 9, 2015 \\ Accepted February 11, 2016 \\ Published March 31, 2016 \\ DOI http://dx.doi.org/10.4238/gmr.15018232
}

ABSTRACT. We performed an exploratory study by analyzing the correlation of 46, XY disorders of sex development (46, XY DSD) with androgen receptor (AR) and steroid $5 \alpha$-reductase-2 (SRD5A2) gene mutations and a safety analysis of dihydrotestosterone (DHT) gel treatment for pediatric micropenis. We collected samples from 76 pediatric patients with $46, X Y$ DSD and 50 healthy adult men with normal fertility as the control group. The pediatric patients were treated with DHT gel $(0.1-0.3 \mathrm{mg} / \mathrm{kg} / \mathrm{day})$ for three to six months. The extended penis length, testicular volume, and multiple blood parameters were collected before treatment and one, three, and six months after treatment. Of the 76 cases with $46, X Y$ DSD, $31.58 \%$ had hypospadias with micropenis and $6.58 \%$ had male pseudohermaphroditism. Through AR gene screening, it was found that 14 patients had AR point mutations and 22 patients had SRD5A2 mutations. After treatment with $\mathrm{DHT}$, the penis length of the patients significantly improved after one, three, and six months of treatment, with longer treatment times resulting in greater improvement. Before treatment with $\mathrm{DHT}$, the average serum DHT value of patients with $46, X Y$ DSD was $24.29 \mathrm{pg} / \mathrm{mL}$. After one, three, and six months of treatment, this value increased to $430.71,328.9$, and 323.6 
$\mathrm{pg} / \mathrm{mL}$, respectively. We conclude that for pediatric patients who have male hermaphroditism or hypospadias with micropenis, AR and SRD5A2 gene mutation detection should be performed. Local application of DHT gel can promote penis growth effectively without systemic adverse reactions.

Key words: 46,XY; AR gene; Hypospadias; Micropenis; SRD5A2 gene

\section{INTRODUCTION}

Disorder of sex development (DSD) is a pediatric endocrinology disease that is characterized by gender inconformity of external genitalia, gonads, and chromosomes. In 2006, the American Lawson Wilkins Pediatric Endocrine Association and European Society for Pediatric Endocrinology did a long-term retrospective investigation on DSD. They suggested that DSD should be divided into DSD with sex chromosome abnormality, 46, XX DSD, and 46, XY DSD. Forty-six, $X Y$ DSD was designated as the general name for male pseudohermaphroditism (Lee et al., 2006). In 2012, a meeting in Chicago suggested that 45, X/46, XY partial DSD; 45, X/46, XY complete DSD; and mixed DSD should be classified as 46, XY DSD (Rey and Grinspon, 2011). With the improvement of molecular biology technologies, researchers and clinicians have developed a better understanding of the pathogenesis of DSD; however, standardized management of $46, X Y$ DSD is still under exploration.

Generally, in the case of $46, X Y$ DSD, the chromosome is $X Y$ and the gonads are testes. However, there is masculinity deficiency to some degree or even expression of gynecoid externalia. The degree of deficiency of masculinity mainly depends on the level of sex hormones and individual reactions to androgens. Affected by multiple factors, treatment of sexual prosoplasia is in need of multidisciplinary intervention, including comprehensive discussion among psychologists, plastic surgeons, endocrinologists, family members, and patients. In particular, patients' degree of masculinity (penis length), response to androgens, social culture, and quality of future sexual life should be taken into consideration (Bao and Swaab, 2011; El-Sherbiny, 2013).

Involving multiple genes, 46, XY DSD is associated with gonadal differentiation, gonad development, and dysregulation of sex hormones. With the improvement of molecular biological technology, we can improve diagnosis of genes related to 46, XY DSD (Adamovic and Nordenskjöld, 2012). Patients with 46, XY DSD have male genital deficiency, fuzzy external genitals, and gynecoid externalia. If the sex-determining region of the $\mathrm{Y}$ chromosome (SRY) is normal and the gonads are testes, it is found that the major gene mutations occur in the androgen receptor (AR) and steroid-5alpha-reductase, alpha polypeptide 2 (SRD5A2) genes (Barrionuevo et al., 2012). At present, it is reported that there are more than 800 mutations in AR and over 65 in SRD5A2. Mutations include point mutations, deletions, and insertions. With the development of science and technology and the transformation of translational medicine models, genetic diagnostic technology has gradually been popularized, making it possible to learn about diseases at a molecular level.

As reported, the commonly used hormones for treating pediatric micropenis include human chorionic gonadotropin, gonadotropin-releasing hormone, testosterone preparations, and dihydrotestosterone (DHT). They can be applied separately or in combination by means of oral administration, intramuscular injection, intradermal injection, inhalation (nasal spray), or local application. Thyen et al. (2006) found that preoperative local application of DHT could improve postoperative recovery of pediatric hypospadias and reduce postoperative complications. For adult users of DHT gel, few side effects (mainly local skin irritation) were similar to that of testosterone. 
To some degree, DHT had curative effects on micropenis of different causes. In this study, we mainly analyzed AR and SRD5A2 gene mutations of 46, XY DSD patients with different clinical manifestations, and systematically observed the curative effects of DHT gel on pediatric micropenis and drug safety. Furthermore, we probed into the pathogenesis and treatment of $46, X Y$ DSD.

\section{MATERIAL AND METHODS}

\section{General materials}

From April 2013 to May 2015, we collected samples from 76 pediatric patients who had 46, XY DSD and whose gonads were testes from Pediatric Surgery of Binzhou People's Hospital. Types of external genitalia were evaluated according to their initial clinical features, and all the patients were diagnosed based on clinical signs and basic hormone levels. Fifty unrelated healthy adult men with normal fertility were selected as the control group. Informed consent was obtained from parents and children and all examinations were approved by Binzhou People's Hospital Ethics Committee.

\section{Clinical evaluation}

Clinical evaluation for the pediatric patients included complaints, history of present illness, birth history, personal history, family history, maternal pregnancy history, previous operation history, hormone therapy history, living environment, and history of contact with environmental pollutants. Physical examination involved measurement of height, weight, extended penis length, testicular volume size, and male genital evaluation (Prader evaluation). All the measurements were performed between 8:00 a.m. and 10:00 a.m. to reduce error.

\section{Diagnostic criteria of micropenis}

With stretched penis length as standard, the children whose standard deviations were more than 2.5 below the average of normal values for the same age were diagnosed as having micropenis. Among the 30 cases ( 7 cases of merely micropenis, 7 cases of micropenis with cryptorchidism, and 16 cases of micropenis with hypospadias), 6 could not urinate standing up due to micropenis. Family members of these children strongly demanded improvement of children's externalia development. With the consent of parents and approval of Binzhou People's Hospital Ethics Committee, the children were treated with external application of DHT gel.

\section{Statistical methods}

The software Stat 11 was used for statistical analysis of the clinical data. Paired $t$-test or Wilcox sign-rank test was performed to determine the differences in groups. $\mathrm{P}<0.05$ indicated that the difference was statistically significant.

\section{RESULTS}

\section{Relationship between genital anomaly types and genotypes of the 76 cases}

As shown in Table 1, of the 76 pediatric patients, 46 had hypospadias with micropenis (of 
which 24 had genetic abnormalities, accounting for 31.58\%); 16 had merely micropenis (2 of which had SRD5A2 gene mutations); and 8 had male pseudohermaphroditis (5 of which had genetic mutations, accounting for $6.58 \%)$.

Table 1. Relationship between genital anomaly types and genotypes of the 76 cases.

\begin{tabular}{l|c|c|c|c|c|c|c}
\hline \multirow{2}{*}{ Genital exception types } & \multirow{2}{*}{ Total cases } & \multicolumn{2}{|c|}{ AR mutation } & \multicolumn{2}{c|}{ SRD5A2 mutation } & \multicolumn{2}{c}{ Total of mutation } \\
\cline { 3 - 8 } & & Cases & $\%$ & Cases & $\%$ & Cases & $\%$ \\
\hline Balanic hypospadias & 6 & 2 & 2.63 & 2 & 2.63 & 4 & 5.26 \\
\hline Penoscrotal hypospadias & 21 & 3 & 3.95 & 12 & 15.79 & 14 & 18.42 \\
\hline Penile hypospadias & 6 & 2 & 2.63 & 2 & 2.63 & 2 & 2.63 \\
\hline Perineal hypospadias & 13 & 5 & 6.58 & 0 & 0.00 & 4 & 5.26 \\
\hline Micropenis & 16 & 0 & 0.00 & 2 & 2.63 & 2 & 2.63 \\
\hline Micropenis with cryptorchidism & 6 & 0 & 0.00 & 0 & 0.00 & 0 & 0.00 \\
\hline Gynecoidexternalia & 8 & 4 & 5.26 & 5 & 6.58 & 5 & 6.58 \\
\hline
\end{tabular}

\section{Results of AR gene mutation screening}

Through AR gene mutation screening of the 76 patients, 14 patients had AR gene point mutations (Figure 1), including 4 cases in exon 2 (c.1670A > G, p.Q557R), 4 cases in exon 7 (three cases of c.2567G > A, p.R856H, one case of c.2522G > T, p.R841L), 4 cases in exon 8 (two cases of c. $2612 \mathrm{C}>\mathrm{T}$, p.A871V, two cases of c.2668G > A, p.V890M), and 2 cases of nonsense mutations (c.2667G > A, p.S889 S, located in exon 8). Among these mutations, p.R856H, p.R841L, p.A871V, and p.V890M were known mutation loci that lead to androgen insensitivity syndrome. However, p.Q557R is a newly identified mutation. According to the test on the mutation loci, p.Q557R, p.R856H, p.R841L, p.A871V, p.V890M, and p.S889S were not found.

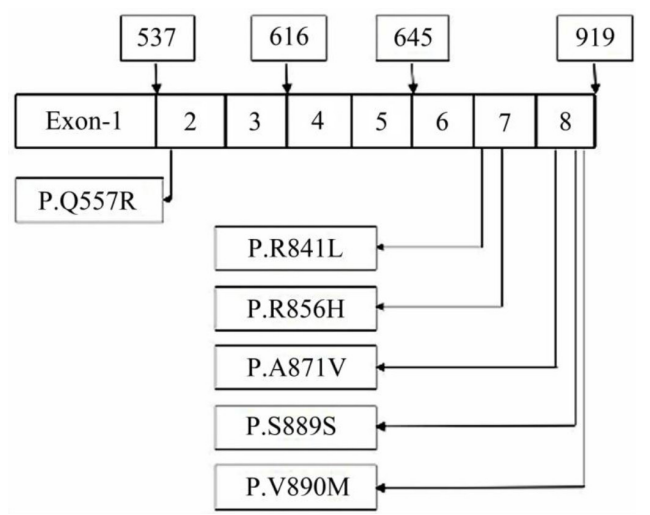

Figure 1. Results of AR gene mutation test of 76 pediatric patients.

\section{Function prediction analysis of AR gene mutation protein}

p.R856H, p.R841L, p.A871V, and p.V890M were reported to be related to complete androgen insensitivity syndrome (CAIS) or partial androgen insensitivity syndrome (PAIS). It was predicted that the p.Q557R mutation might affect the function of the encoded protein. 


\section{Screening results of SRD5A2 gene mutation}

Of the 76 patients, there were 22 cases of SRD5A2 gene pathogenic mutations. Two cases were in exon 1 (c.59T > C, p.L20P) and 20 cases in exon 4 (7 cases of c.607G > A, p.G203S/ c.680G > A, p.R227Q; 2 cases of C.680G > A, p.R227Q/c.6830T, p.A228V; 2 cases of c.683C > T, p.A228V; 7 cases of c.680G > A, p.R227Q; and 2 cases of c.663_664_delTTP.C222Vfs 225X). The pathogenic mutation loci (Figure 2) included p.L20P, p.G203S, p.R227Q, p.A228V, and p.C222Vfs 225X. There were four cases of compound heterozygous mutations and eight cases of $p . R 227 Q$ mutations. p.L20P, p.G203S, p.R227Q, and p.A228V have been previously reported, whereas p.C222Vfs $225 \mathrm{X}$ is a novel mutation. p.L20P, p.G203S, p.R227Q, p.A228V, and p.C222Vfs 225X locus mutations were not found, and V89L and 281+15T > C (exon 1 of SRD5A2 gene) were identified in both patients and controls.

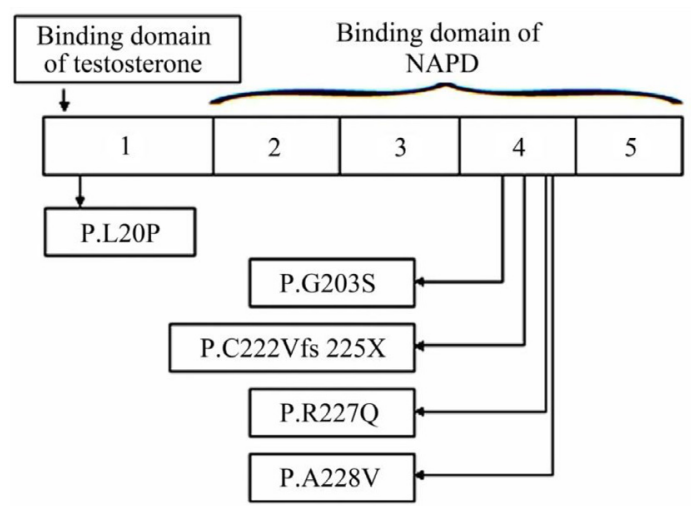

Figure 2. SRD5A2 gene mutations in76 pediatric patients.

\section{Analysis of polymorphism loci of SRD5A2 exon 1 in 76 cases of pediatric patients and 50 cases of healthy fertile men}

Polymorphism loci of SRD5A2 exon 1 are shown in Table 2. Through chi-square test, a value of $P=0.346$ was obtained, which means there is no statistical difference between the two groups.

\section{Table 2. Polymorphism loci analysis of SRD5A2 exon 1.}

\begin{tabular}{l|c|c}
\hline Polymorphism loci & Control group $(\mathrm{N}=50)$ & Patients $(\mathrm{N}=76)$ \\
\hline c. 265 C > G,p.L89V & 6 & 16 \\
\hline c. $281+15 T>$ C & 21 & 23 \\
\hline c. 265 C > G,p.L89V \& c.281+15T > C & 23 & 35 \\
\hline
\end{tabular}

\section{Function prediction analysis of SRD5A2 gene mutation protein}

SRD5A2 gene loci p.G203S and p.R227Q have been reported to reduce activity of $5 \alpha$ reductase. It was predicted that SRD5A2 gene mutation locus p.L20P might affect the function of the encoded protein. Through the NCBI website, we found that p.C222Vfs mutation in SRD5A2 could lead to premature translational termination. 


\section{Curative effect analysis of DHT gel on pediatric micropenis}

Before medication, penis length in 46 cases was $1.68 \pm 0.6 \mathrm{~cm}$ and $\Delta$ penis lengthstandard deviation score $(\triangle \mathrm{PL}-\mathrm{SDS})$ was $-1.13 \pm 0.47 \mathrm{~cm}$. After one month of medication, 41 children had a follow-up visit, and penis length was $2.2 \pm 0.65 \mathrm{~cm}$ and $\Delta \mathrm{PL}-\mathrm{SDS}$ was $-0.54 \pm 0.51$ $\mathrm{cm}$ (comparing the penis length before and after one month of medication, $\mathrm{P}<0.05)$. After three months of medication, 37 children had a follow-up visit, and penis length was $2.54 \pm 0.57 \mathrm{~cm}$ and $\triangle \mathrm{PL}-\mathrm{SDS}$ was $-0.28 \pm 0.74 \mathrm{~cm}$ (comparing the penis length before and after three months of medication, $\mathrm{P}<0.001$ ). After six months of medication, 25 children had a follow-up visit, and penis length was $3.01 \pm 0.70 \mathrm{~cm}$ and $\triangle P L-S D S$ was $0.24 \pm 0.51 \mathrm{~cm}$ (comparing the penis length before and after six months of medication, $\mathrm{P}<0.001$ ). At present, 35 patients have finished treatment. Twelve patients discontinued medication after three months; of these, five achieved -2.5 standard deviation (SD), another five reached standard penis length, and two were not up to the standard for drug withdrawal. Twenty-three discontinued medication after six months; of these, 18 reached standard penis length and five nearly reached the standard length (three of them could pee standing up). The cases discussed above are shown in Figure 3.

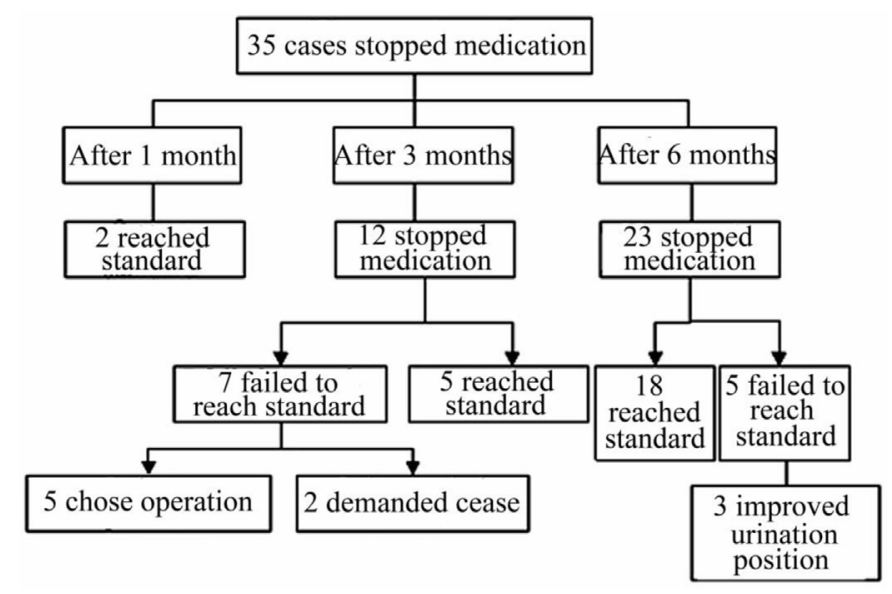

Figure 3. Cases of medication and follow-up visit of the 35 patients.

Forty-six patients had follow-up visits and applied DHT gel in treatment. After one month of medication, penis length grew by $0.58 \mathrm{~cm}$ on average for 41 patients. After three months of medication, penis length grew by $1.02 \mathrm{~cm}$ on average for 37 patients. After six months of medication, penis length grew by $1.51 \mathrm{~cm}$ on average for 25 patients.

\section{Curative effect analysis of DHT gel on patients with SRD5A2 gene mutation}

Among the 35 patients who discontinued medication, six had $5 \alpha$ reductase defects. After six months of medication, the six cases reached SD of -2.5 and their penis length increased by $1.4 \pm 0.13 \mathrm{~cm}$ on average. Comparing average increase value of penis length of the six cases with $5 \alpha$ reductase defects to the 22 cases with non- $5 \alpha$ reductase defects, there was no statistical difference between them $(t=-0.7716, \mathrm{P}=0.4556)$. 


\section{Curative effect analysis of DHT gel on micropenis and micropenis with hypospadias}

Among the 46 patients in this group, 25 had micropenis with hypospadias and 20 had no hypospadias. After three months of treatment (of DHT gel), 17 patients from the non-hypospadias group had a follow-up visit and penis length had increased by $1.01 \pm 0.21 \mathrm{~cm}$. Twenty-three patients from the hypospadias group had a follow-up visit and penis length had increased by $1.04 \pm 0.27$ $\mathrm{cm}$. Based on statistical analysis of the two groups, $t=-0.3613$ and $\mathrm{P}=0.7226$. After six months of medication of DHT gel, 10 patients from the non-hypospadias group had a follow-up visit and penis length had increased by $1.56 \pm 0.33 \mathrm{~cm}$. Twelve patients from the hypospadias group had a follow-up visit and penis length had increased by $1.41 \pm 0.33 \mathrm{~cm}$. Based on statistical analysis of the two groups, $t=-0.6606$ and $\mathrm{P}=0.5248$ (Figure 4).

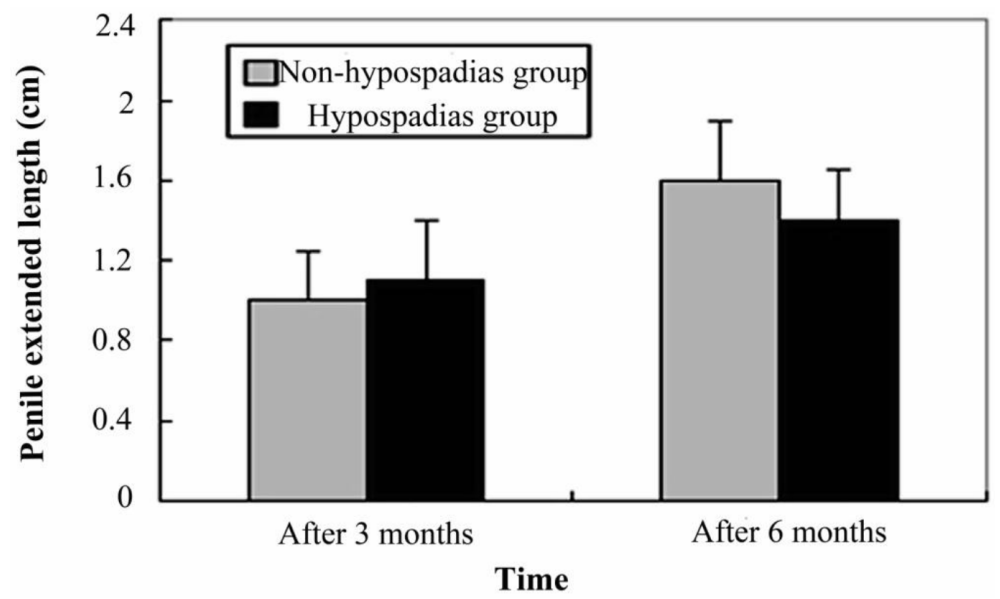

Figure 4. Curative effect analysis of DHT gel on micropenis with or without hypospadias.

\section{Safety indicator analysis of DHT gel on pediatric micropenis}

Before treatment and after one, three, and six months of treatment, routine blood, hepatorenal function, and sex hormone levels of the patients were monitored and used for $t$-test or rank sum test. Comparing the indicators of different periods, it could be observed whether there were differences $(P<0.05)$. Routine blood indicators include white blood cells, hemoglobin, red blood cells, and platelets. Hepatorenal function indicators include alanine aminotransferase, aspartate transferase, blood urea nitrogen, and creatinine. Sex hormones include follicle stimulating estrogen, luteinizing hormone, estradiol, and testosterone. Additionally, blood concentration of DHT was monitored. Data of the indicators are shown in Tables 3, 4, and 5.

In addition, it was found that the average serum DHT value of 46 patients was $24.29 \mathrm{pg} / \mathrm{mL}$ before treatment with DHT gel. After one month of treatment, the average DHT value of 41 patients was $430.71 \mathrm{pg} / \mathrm{mL}$. After three months of medication, the average DHT value of 37 patients was $328.9 \mathrm{pg} / \mathrm{mL}$. After six months of medication, the average DHT value of 25 patients was $323.6 \mathrm{pg} /$ $\mathrm{mL}$. To sum up, after medication, DHT values were maintained close to values of Tunner III period. 
Table 3. Monitoring of routine blood indicators of 18 pediatric patients (mean \pm SD).

\begin{tabular}{l|c|c|c|c|c|c|c|c|c|c}
\hline Indicators & 0 month & 1st month & 3rd month & 6th month & $\mathrm{t}^{*}$ & $\mathrm{p} 1^{*}$ & $\mathrm{t}^{\#}$ & $\mathrm{p} 3^{\#}$ & $\mathrm{t} 6^{\&}$ & $\mathrm{p6}^{8}$ \\
\hline $\mathrm{Hg}(\mathrm{g} / \mathrm{L})$ & $127 \pm 15.1$ & $126 \pm 13.1$ & $126 \pm 14.5$ & $127 \pm 12.5$ & 0.21 & 0.83 & 0.18 & 0.85 & -0.42 & 0.96 \\
\hline $\mathrm{Rbc}\left(10^{12} / \mathrm{L}\right)$ & $4.75 \pm 0.42$ & $4.62 \pm 0.43$ & $4.86 \pm 0.13$ & $4.78 \pm 0.50$ & 0.95 & 0.34 & -0.71 & 0.46 & -0.27 & 0.75 \\
\hline $\mathrm{Wbc}\left(10^{9} / \mathrm{L}\right)$ & $9.01 \pm 1.93$ & $8.98 \pm 2.30$ & $8.18 \pm 2.45$ & $8.42 \pm 2.37$ & 0.03 & 0.96 & 1.05 & 0.27 & 0.66 & 0.51 \\
\hline $\mathrm{Plt}\left(10^{9} / \mathrm{L}\right)$ & $291 \pm 58.1$ & $286 \pm 107.68$ & $270 \pm 88.9$ & $279 \pm 73.6$ & 0.14 & 0.87 & 0.73 & 0.46 & 0.44 & 0.63 \\
\hline
\end{tabular}

$\mathrm{Hg}=$ hemoglobin; $\mathrm{Rbc}=$ red blood cell count; $\mathrm{wbc}=$ white blood cell count; $\mathrm{Plt}=$ platelet count; $\mathrm{t}^{*}$ and $\mathrm{p} 1^{*}$, comparison between routine blood indicators in 0 month (before medication) and 1st month (after one-month medication), respectively; $\mathrm{t}^{\#}$ and $\mathrm{p} 3^{\#}$, comparison between routine blood indicators in 0 month and 3rd month, respectively; $\mathrm{t}^{\star}$ and $\mathrm{p} 6^{\&}$, comparison between routine blood indicators in 0 month and 6th month, respectively.

Table 4. Monitoring of hepatorenal function indicators (means $\pm \mathrm{SD}$ ).

\begin{tabular}{l|c|c|c|c|c|c|c|c|c|c}
\hline Indicators & 0 month & 1st month & 3rd month & 6th month & $\mathrm{t} 1 / \mathrm{z} 1$ & $\mathrm{p} 1$ & $\mathrm{t} 3 / \mathrm{z3}$ & $\mathrm{p} 3$ & $\mathrm{t} 6 / \mathrm{z6}$ & $\mathrm{p} 6$ \\
\hline Alt & $9.4(8.0-11.7)$ & $10(8.1-13.7)$ & $9.4(8.1-13.7)$ & $10(7.2-15.2)$ & -0.42 & 0.66 & -0.22 & 0.82 & -0.11 & 0.97 \\
\hline Ast & $18(17-22)$ & $18(15-23)$ & $20(16-24)$ & $20(13-22)$ & 0.04 & 0.95 & -0.16 & 0.86 & 0.03 & 0.96 \\
\hline Bun & $4.04 \pm 1.83$ & $4.43 \pm 1.24$ & $4.72 \pm 1.41$ & $5.13 \pm 1.32$ & -0.71 & 0.45 & -1.18 & 0.23 & -1.71 & 0.12 \\
\hline Cr & $26.2 \pm 10.41$ & $28.5 \pm 9.78$ & $28.0 \pm 7.17$ & $27.1 \pm 8.64$ & -0.67 & 0.48 & -0.59 & 0.56 & -0.24 & 0.82 \\
\hline
\end{tabular}

Alt = alanine aminotransferase $(\mathrm{U} / \mathrm{L}) ;$ Ast $=$ aspartate transferase $(\mathrm{U} / \mathrm{L}) ;$ Bun = blood urea nitrogen $(\mathrm{mM}) ; \mathrm{Cr}=$ creatinine $(\mu \mathrm{M})$; means $\pm \mathrm{SD}$, conforming to the normality test; median (p25-p27) represents not in conformity with the normality test; $\mathrm{t}=$ paired $\mathrm{t}$-test; $\mathrm{z}=\mathrm{z}$ values of rank sum test.

Table 5. Monitoring of sex hormone level indicators (means \pm SD).

\begin{tabular}{l|c|c|c|c|c|c|c|c|c|c}
\hline Indicators & 0 month & 1st month & 3rd month & 6th month & $\mathrm{z} 1^{*}$ & $\mathrm{p} 1^{*}$ & $\mathrm{z}^{\#}$ & $\mathrm{p} 3^{\#}$ & $\mathrm{z6}^{\&}$ & $\mathrm{p6}^{\text {\& }}$ \\
\hline Fsh & $1.81(1.27-3.1)$ & $1.46(0.92-3.55)$ & $1.13(0.72-3.25)$ & $1.27(0.66-4.15)$ & 0.75 & 0.45 & 1.42 & 0.14 & 0.74 & 0.46 \\
\hline Lh & $0.85(0.21-2.54)$ & $0.64(0.32-1.94)$ & $0.24(0.15-1.36)$ & $0.42(0.12-1.23)$ & 0.24 & 0.81 & 1.36 & 0.17 & 1.32 & 0.21 \\
\hline E2 & $4.46(0-13.7)$ & $7.14(0-9.62)$ & $1.64(0-4.35)$ & $2.35(0-8.59)$ & -0.44 & 0.67 & 1.25 & 0.22 & 0.72 & 0.49 \\
\hline T & $0(0-13.5)$ & $0(0-0.64)$ & $0(0-1.07)$ & $0(0-0)$ & 0.51 & 0.63 & 1.14 & 0.26 & 1.04 & 0.31 \\
\hline
\end{tabular}

Fsh = follicle stimulating hormone $(\mathrm{mlU} / \mathrm{mL}) ; \mathrm{Lh}=$ luteinizing hormone $(\mathrm{mlU} / \mathrm{mL}) ; \mathrm{E} 2=$ estradiol $(\mathrm{pg} / \mathrm{mL}) ; \mathrm{T}=$ testosterone $(\mathrm{pg} / \mathrm{mL}) ; \mathrm{z} 1^{*}$ and $\mathrm{p} 1^{*}$, comparison between sex hormone indicators in 0 month and 1 st month, respectively; $z 3^{\#}$ and $\mathrm{p} 3^{\#}$, comparison between sex hormone indicators in 0 month and 3rd month, respectively; $z 6^{\&}$ and $p 6^{\&}$, comparison between sex hormone indicators in 0 month and 6th month, respectively.

\section{DISCUSSION}

Male hypospadias, micropenis, and male pseudohermaphroditism are the common clinical manifestations of pediatric genital disorders of 46, XY DSD. Androgen insensitivity syndrome (AIS) and $5 \alpha$ reductase type- 2 deficiency, which result from androgen receptors and metabolic disorders of androgen peripheral tissues, show varying degrees of masculinity deficiency. According to studies, AIS and $5 \alpha$ reductase type- 2 deficiency are the major causes of $46, X Y$ DSD, accounting for about $50 \%$ of XY DSD (Mendonca et al., 2010). Through studies on clinical manifestations, biochemical examination, and genetic testing of 58 patients with 46, XY DSD, Veiga-Junior et al. (2012) came to the following conclusions: for 46, XY DSD patients with undistinguishable genitals, SRD5A2 gene testing is the first option; for patients who have relevant family history, AR gene testing is the first option. This study involved 76 cases of $46, X Y$ DSD patients; they had 
46 chromosomes and their $\mathrm{XY}$ and SRY genes were normal, which ruled out the possibility that chromosomal abnormalities or SRY genes led to male gonad dysplasia. Through AR and SRD5A2 gene sequencing analysis of the 76 patients, it was found that AR and SRD5A2 gene abnormalities resulted in micropenis (accounting for 31.58\%) and male pseudohermaphroditism (accounting for $6.58 \%)$, which were similar to other analysis results.

The AR gene mutation database summarized 800 types of cases in which AR mutations led to AIS, and reported research on 45 kinds of gene mutations and phenotypes (Knower et al., 2011). Mutation loci p.R841L, p.R856H, p.A871V and p.V890M, which were reported before, were also found in this study; in addition, it was reported that p.R841L could lead to PAIS. One of the patients in this study had penile hypospadias and micropenis; his mother had a heterozygous mutation and his cousins had similar medical history. Therefore, the patient was diagnosed with PAIS. It was reported that p.R856 could lead to CAIS, PAIS, or mild androgen insensitivity syndrome (MAIS). One patient had perineal hypospadias and micropenis, and his mother had a heterozygous mutation. There was an infertile patient in his family and therefore the patient was diagnosed with PAIS. It was reported that p.A871V could lead to PAIS and MAIS. One of the patients had balanic hypospadias and micropenis and, without information on his family history and his parents' genetic information, the patient was considered to have PAIS. It has been reported that p.V890M led to CAIS and PAIS. One patient had gynecoid genitalia and his mother had a heterozygous mutation. This patient was diagnosed with CAIS, advised to remove his testes in adolescence, and raised as a female. Two patients from the same family were heterozygous for the p.Q557R mutation in AR gene exon 2 and homozygous for the p.R227Q mutation in the SRD5A2 gene exon 4 . Their mother had heterozygous mutations at the corresponding loci of the AR and SRD5A2 genes, whereas their father was only heterozygous for the SRD5A2 gene mutation. Their mother had four sisters, three of whom were fertile and the other was not married, and the patients' grandmother had a brother with normal fertility. Moreover, genotypes of the two patients were consistent even though they had different clinical manifestations. One patient had gynecoid genitalia with clitoral hypertrophy, there was no vagina, and the bilateral labium majus could reach the testes. Another patient had penile hypospadias and micropenis. It was reported that the p.R227Q mutation in the SRD5A2 gene could reduce the activity of $5 \alpha$ reductase 2 , and this mutation was found to reduce the activity of $5 \alpha$ reductase in Asian populations, retaining only $3.2 \%$ of normal activity (Walter et al., 2010). The newly identified AR mutation p.Q557R was located in exon 2 (DNA-binding domain). The two patients were both heterozygous for the AR mutation but without related family history. Therefore, it was speculated that the two patients might be chromosomal chimaera. To judge whether p.Q557R changes androgen receptor functions, further improvement of functional tests and confirmation are required.

Many reports have found that both patients and healthy controls had homozygous mutations (p.V89L and c.281 + 15T > C). Based on SRD5A2 gene exon sequencing analysis of 76 patients (with another 50 healthy and fertile men as control), we found that there were three types of loci: c. 265 C > G, p.L89V; c.281+15T > C; and c. 265C > CG \& c. $281+15 T$ > TC. Through the chi-square test, there was no statistical difference between experimental and control groups. Other research has found that c.265C > G and p.L89V mutations were related to sperm quality (Massanyi et al., 2013), severe hypospadias (Akcay et al., 2014), and prostate cancer risk (Gottlieb et al., 2012).

Based on the comparison between micropenis with and without hypospadias, there was no significant difference in curative effects. Through comparison of genotypes, it was found that for the patients with or without SRD5A2 gene defects, there was no obvious difference in curative effects of DHT gel. After medication, the penis length increased for all patients, which indicated that DHT gel could treat micropenis of different causes. DHT is a metabolic product of testosterone. In 
a hamster experiment, it was found that compared to testosterone and male dilute diketone, DHT was the most effective for promoting growth of the penis (Tsai et al., 2012).

The effects of DHT on body organs are similar to that of testosterone, including effects on erythropoiesis, lipid metabolism, hepatorenal function, prostate function, and bone mineralization. Charmandari et al. (2001) reported that DHT gel was effective in treating micropenis, maintaining normal hepatorenal function and increasing serum DHT levels up to adult level. Kaya et al. (2008) adopted local application of DHT gel to assist surgery in treatment of hypospadias. It was found that there were fewer postoperative complications and a more aesthetic shape, in which case DHT gel could increase local blood flow.

In brief, for pediatric patients with male hermaphroditism or hypospadias, detection of mutation in AR and SRD5A2 genes is the first option. It is still unclear whether protein length of $A R$ influences the activity of androgen receptors. The mutations c.680G > A and p.R227Q in the SRD5A2 gene might be hotspot mutations for hypospadias. This study found that local application of DHT gel could promote penis growth in treatment of micropenis. After one month, the penis grew by $0.58 \mathrm{~cm}$ on average; after three months, the penis grew by $1.02 \mathrm{~cm}$ on average; and after six months, the penis grew by $1.5 \mathrm{~cm}$ on average. However, since the sample size was small and the follow-up visit time was not long enough, more studies are needed to observe the long-term curative effects of DHT gel.

\section{Conflicts of interest}

The authors declare no conflict of interest.

\section{ACKNOWLEDGMENTS}

My deepest gratitude goes to Professor Xiuhua Fu and Wenqian Zhang for their constant guidance and encouragement. I am also sincerely grateful to my family and friends who have always been there to give me faith.

\section{REFERENCES}

Adamovic T and Nordenskjöld A (2012). The CAG repeat polymorphism in the androgen receptor gene modifies the risk for hypospadias in Caucasians. BMC Med. Genet. 13: 109.http://dx.doi.org/10.1186/1471-2350-13-109

Akcay T, Fernandez-Cancio M, Turan S, Güran T, et al. (2014). AR and SRD5A2 gene mutations in a series of 51 Turkish 46,XY DSD children with a clinical diagnosis of androgen insensitivity. Andrology 2: 572-578.http://dx.doi.org/10.1111/ i.2047-2927.2014.00215.x

Bao AM and Swaab DF (2011). Sexual differentiation of the human brain: relation to gender identity, sexual orientation and neuropsychiatric disorders. Front. Neuroendocrinol. 32: 214-226.http://dx.doi.org/10.1016/j.yfrne.2011.02.007

Barrionuevo FJ, Burgos M, Scherer G and Jiménez R (2012). Genes promoting and disturbing testis development. Histol. Histopathol. 27: 1361-1383.

Charmandari E, Dattani MT, Perry LA, Hindmarsh PC, et al. (2001). Kinetics and effect of percutaneous administration of dihydrotestosterone in children. Horm. Res. 56: 177-181.http://dx.doi.org/10.1159/000048115

El-Sherbiny M (2013). Disorders of sexual differentiation: II. Diagnosis and treatment. Arab J Urol 11: 27-32.http://dx.doi. org/10.1016/j.aju.2012.11.008

Gottlieb B, Beitel LK, Nadarajah A, Paliouras M, et al. (2012). The androgen receptor gene mutations database: 2012 update. Hum. Mutat. 33: 887-894.http://dx.doi.org/10.1002/humu.22046

Kaya C, Bektic J, Radmayr C, Schwentner C, et al. (2008). The efficacy of dihydrotestosterone transdermal gel before primary hypospadias surgery: a prospective, controlled, randomized study. J. Urol. 179: 684-688.http://dx.doi.org/10.1016/j. juro.2007.09.098 
Knower KC, Kelly S, Ludbrook LM, Bagheri-Fam S, et al. (2011). Failure of SOX9 regulation in 46XY disorders of sex development with SRY, SOX9 and SF1 mutations. PLoS One 6: e17751.http://dx.doi.org/10.1371/journal.pone.0017751

Lee PA, Houk CP, Ahmed SF and Hughes IA; International Consensus Conference on Intersex organized by the Lawson Wilkins Pediatric Endocrine Society and the European Society for Paediatric Endocrinology (2006). Consensus statement on management of intersex disorders. Pediatrics 118: e488-e500.http://dx.doi.org/10.1542/peds.2006-0738

Massanyi EZ, Gearhart JP, Kolp LA and Migeon CJ (2013). Novel mutation among two sisters with $17 \beta$ hydroxysteroid dehydrogenase type 3 deficiency. Urology 81: 1069-1071.http://dx.doi.org/10.1016/j.urology.2012.12.024

Mendonca BB, Costa EM, Belgorosky A, Rivarola MA, et al. (2010). 46,XY DSD due to impaired androgen production. Best Pract. Res. Clin. Endocrinol. Metab. 24: 243-262.http://dx.doi.org/10.1016/j.beem.2009.11.003

Rey RA and Grinspon RP (2011). Normal male sexual differentiation and aetiology of disorders of sex development. Best Pract. Res. Clin. Endocrinol. Metab. 25: 221-238.http://dx.doi.org/10.1016/j.beem.2010.08.013

Thyen U, Lanz K, Holterhus PM and Hiort O (2006). Epidemiology and initial management of ambiguous genitalia at birth in Germany. Horm. Res. 66: 195-203.http://dx.doi.org/10.1159/000094782

Tsai MC, Chou YY, Lin SJ and Tsai LP (2012). A novel SRD5A2 mutation in a Taiwanese newborn with ambiguous genitalia. Kaohsiung J. Med. Sci. 28: 231-235.http://dx.doi.org/10.1016/j.kims.2011.10.011

Veiga-Junior NN, Medaets PA, Petroli RJ, Calais FL, et al. (2012). Clinical and laboratorial features that may differentiate 46,XY DSD due to partial androgen insensitivity and 5 $\alpha$-reductase type 2 deficiency. Int. J. Endocrinol. 2012: 964876.http:// dx.doi.org/10.1155/2012/964876

Walter KN, Kienzle FB, Frankenschmidt A, Hiort O, et al. (2010). Difficulties in diagnosis and treatment of $5 \alpha$-reductase type 2 deficiency in a newborn with 46,XY DSD. Horm. Res. Paediatr. 74: 67-71.http://dx.doi.org/10.1159/000313372 